Methods We studied young women aged 12-18 years, 'looked after' by three Local Authorities co-terminus with our Health Board's geographical area, who by virtue of their age should have received a 3 dose HPV vaccination course. We compared vaccination coverage in this group, using their recorded vaccination status on the All Wales Child Health Database, with a cohort of young women who were not 'looked after', and who had completed academic year 9 and were resident in the same Health Board area, using NPHS Wales 'COVER' data. We statistically analysed differences observed. We established that ethical approval was not required to undertake this study.

Results Of 2555 young women who had completed year 9 and who were not 'looked after', 2308 had completed a 3 dose HPV vaccination course (90.3\%). Of the 157 eligible young women 'looked after', 131 had received a comparable 3 dose vaccination course $(83.4 \%)$. The difference was statistically significant $\left(\mathrm{X}^{2}\right.$ 7.763, p 0.005).

Conclusion Our study of young women who should have completed a 3 dose HPV vaccination course highlights that those 'looked after' were significantly less likely to be vaccinated. We have identified yet another area of health disadvantage for this group which could have important consequences for their future health. Action is required to address this and our own recommendations will be discussed, in addition to what we see as the possible reasons for this difference. We suggest that HPV vaccination coverage rates in young women 'looked after' should be reviewed across the United Kingdom by those health professionals who work with this vulnerable group.

\section{G498(P) ARE WE FAILING OUR CHILDREN AND OUR FUTURE? INTRODUCING MEDICAL STUDENTS TO CHILD HEALTH INEQUALITIES}

B Morrissey, P Powell, J Moreiras. Paediatrics, Whittington Hospital NHS Trust, London, UK

10.1136/archdischild-2015-308599.451

Background and aims Huge inequalities exist in child health globally. Current under five mortality rates vary significantly between countries from 2.3 per 1000 live births in Singapore to 152.5 per 1000 live births in Guinea-Bissau. In the UK, children from poorer socio-economic backgrounds are more likely to be born small, die during their first year of life and die from an accident in childhood. We aimed to develop and evaluate a student-selected component (SSC) introducing medical students to inequalities in child health.

Methods The student-selected component (SSC) ran one afternoon a week for eight weeks. Students participated in four interactive workshops on topics around child inequality and attended a relevant paediatric clinic or service. Students completed a selfdirected project exploring an area of possible inequality for children, produced a poster and gave a short presentation at the end of the SSC, which was assessed. We evaluated the SSC by e-mailing a structured questionnaire to all participants and analysed responses thematically.

Results Twelve second year students undertook the SSC. All 12 completed the post-programme questionnaire. Medical students gained the following from participating in the SSC:
1. An increased understanding of the inequalities that exist in child health. "I was quite shocked at how large the differences were especially within the UK.

2. Research and presentation skills.

3. An awareness of the need for effective interventions to reduce inequality and improve children's health. "It's not just a matter of throwing money towards services for children but preventing the inequalities from happening in the first place."

4. An increased motivation to see the situation improve. "This has fired me up to want to do something about this in the future."

Seven out of 12 students (58\%) reported that doing the SSC had either confirmed or increased their desire to pursue paediatrics as a career. Three further students reported they had wanted to do paediatrics before doing the SSC.

Conclusions Introducing medical students to child health inequalities early on in their undergraduate training can have significant benefits, particularly in helping students to understand the broader social determinants of health, and encouraging more medical students to take up careers in child health.

\section{G499(P) CHILD SAFETY AWARENESS IN MEDICAL STUDENTS: A NEED FOR THE LOLLIPOP LADY}

${ }^{1} \mathrm{~S}$ Bali, ${ }^{2} \mathrm{H}$ Jacob, ${ }^{2} \mathrm{C}$ Fertleman. ${ }^{1}$ Paediatric Accident and Emergency Department, Chelsea and Westminster Hospital, London, UK; ${ }^{2}$ Department of Paediatrics, The Whittington Hospital, London, UK

\subsection{6/archdischild-2015-308599.452}

Aims Advocating to improve child safety, as part of child health promotion, is integral to the role of all doctors working with children. Many general practitioners and doctors in training shy away from providing such advice to families because they lack the knowledge, missing important opportunities to prevent accidents in children. Variation in postgraduate rotations make medical school an ideal time to learn about child safety, a practice followed in the United States of America.

Our study explored medical students knowledge, skills and attitudes towards providing guidance about child safety.

Methods We sent a survey to all medical students undertaking their paediatric placement at one teaching hospital between 2012-13. We asked them if they felt comfortable giving advice about preventing sudden unexpected infant death, drowning and choking as well as cardiopulmonary resuscitation (CPR) and first aid. We also enquired from them about the commonest causes of death in children under five and the risk factors for accidental deaths in children.

We collected the data using SurveyMonkey ${ }^{\mathrm{TM}}$ software and analysed it using Microsoft Excel ${ }^{\mathrm{TM}}$.

Results 82 students were approached, 49(60\%) responded. Most [32(65\%)] felt uncomfortable giving parents advice about preventing sudden unexpected death in an infant, many [22 (47\%)] about drowning advice and some [19(39\%)] about preventing choking. 15(30\%) felt uncomfortable giving parents advice about CPR and first aid. 27(55\%) thought that accidents were a leading cause of death in children under five. 49(100\%) learnt about child safety from personal experience while 26 $(53 \%)$ learn about it from general practice or child health placements. 
$43(88 \%)$ of respondents wanted these topics to be covered during medical school. A recent survey of 56 UK paediatricians and general practitioners rated highly the importance of undergraduate knowledge of accident prevention $3.7 / 5$ and ability to engage in health promotion $4 / 5$.

Conclusions This study demonstrates a lack of confidence and competence among medical students to provide advice about child safety despite clinicians considering this topic essential to undergraduate knowledge. Efforts must be made to improve the quality of child safety and child health promotion advice given to parents and undergraduate training provides an ideal opportunity to develop these skills.

\section{G500(P) EARLY NUTRITION FOR LATER HEALTH: WHY 'EARLY' SHOULD START IN PREGNANCY}

J More. School of Health Professions, Plymouth University, Plymouth, UK

10.1136/archdischild-2015-308599.453

\section{Aims}

1. To research the evidence base underpinning the short and long term effects of nutritional status and insufficiency during fetal and infant life

2. To assess the knowledge base of healthcare professionals and the resources available to them and parents to optimise nutritional advice for families during this key developmental period

\section{Methods}

1. An extensive literature search and interviews with key experts in the field

2. Qualitative and quantitative surveys of 150 healthcare professionals and 1,000 mothers/mothers-to-be to understand perceptions/attitudes and the level of knowledge about the impact of nutrition and lifestyle during preconception, pregnancy, infancy and the preschool years on health outcomes.

Results

- Maternal nutritional status and BMI during preconception and pregnancy impacts on programming and development in the fetus, affecting short and long term health outcomes of mother and child

- Maternal obesity and excess gestational weight gain affects hormonal balance and increases risk of complications in pregnancy and obesity in the infant and childhood

- Maternal nutritional status and type of infant feeding affects growth, bone health, risk of some infections and atopic disease in children with a family history of allergy

- Knowledge base and training of some HCPs is inadequate and most would welcome more training and consultation time

- Weighing during pregnancy, calculating pre pregnancy BMI and advising on suitable gestational weight gain is not routine

- Advice on healthy eating and supplementation to ensure adequate intakes of folate, vitamin $\mathrm{D}$, iodine, iron and omega 3 during preconception and pregnancy is not routine

- Mothers would welcome more advice and support during preconception and, pregnancy and on early life nutrition

Conclusion Families need updated, consistent evidence based information on nutrition and weight management preconception, during pregnancy and early life and HCPs need more time, resources and training to effectively deliver this.
G501(P) TO ASSESS THE FUNCTIONAL STATUS, SOCIAL HABITS, AND WORRIES IN A GROUP OF UNACCOMPANIED REFUGEE AND ASYLUM-SEEKING MINORS AND THE IMPLICATIONS OF THESE ON HEALTH BEHAVIOUR AND MENTAL HEALTH

${ }^{1} \mathrm{~A}$ Woods, ${ }^{1,2} \mathrm{C}$ Wood, ${ }^{2} \mathrm{~J}$ Thomas, ${ }^{2} \mathrm{M}$ Abraham. ${ }^{1}$ St Georges University, London, UK; ${ }^{2}$ Charitable Organisation, Caras/KKF, London, UK

\subsection{6/archdischild-2015-308599.454}

Method Unaccompanied minors used a colour sticker system to answer questions about their abilities, function, social habits and desires, and worries during contact sessions with local charity.

Results "I worry about....feeling sad all the time" $83 \%$ respondents

"I worry about....not being able to sleep" 92\% respondents

"I worry about....having nightmares" 66\% respondents

"I worry about....the police" 50\% respondents

"I worry about....my health" 42\% respondents

$55 \%$ described difficulty accessing health services

$42 \%$ interviewed said that if they had a problem they would definitely share it with only 1 person, or no-one.

Conclusions The NHS is currently facing a crisis in providing mental health for young people-many young people with acute mental health needs are unable to access CAMHS beds in the wider area.

Our study has highlighted the potential for mental health problems in a group of young adults where 'feeling sad', 'nightmares' and 'not sleeping' are common occurrences. It is well documented that access to mental health services to asylum seekers during the resettlement period is very poor, however these unaccompanied minors are at further risk as they are on their own and often living with unknown adults and in undesirable accommodation. Protective factors to refugee/asylum seeking children have been documented as good settlement and social support in new country. However, for this specific group of children this is stability they often lack, putting them at further risk.

Studies and recent highly publicised reports have found that children in care are at higher risk of physical and sexual abuse and mental health problems, our study found that $16 \%$ would not feel comfortable sharing a problem with anyone, and a further $25 \%$ would only share it with 1 named role.

Ensuring a proactive approach to mental health in this community is key, small specialist organisations are vital for providing additional support to these unaccompanied minors, providing stability and facilitating positive, trusting relationships with adults.

\section{G502(P) RISK ASSESSMENT OF CHILDREN WITH EATING DISORDERS: A RETROSPECTIVE ANALYSIS OF INPATIENT ADMISSIONS}

C Swinburne. Paediatrics, University Hospital Crosshouse, NHS Ayrshire and Arran, Kilmarnock, UK

\subsection{6/archdischild-2015-308599.455}

Background In 2012 the Royal College of Psychiatrists published the Junior MARSIPAN guideline on the management of anorexia nervosa in patients under 18 years of age. A risk assessment framework was proposed at this time to aid identification of patients at risk of serious complications. 